\section{- lazer a servico do social no setor do comércio: institucionalização e estratégias (1945-1982)}

\section{Leisure as social service in the commerce sector: institutionalization and strategies (1945-1982)}

\section{Resumo}

O objetivo central deste capítulo é relacionar circunstâncias políticas governamentais no Brasil entre os anos de 1945 a 1982, que ambientaram a organização do lazer aos comerciários na Cidade de São Paulo. Com perspectivas que vão desde a criação do Serviço Social do Comércio no Estado São Paulo, assim como todo o processo de suas principais contribuições aos estudos do lazer no Brasil. Estão mencionadas neste estudo algumas estratégias que fizeram da Instituição uma das principais influenciadoras na construção do imaginário do lazer na Cidade de São Paulo; que manteve o foco em ações sociais ao comerciário e prestadores de serviço desde o seu perfil inicialmente "assistencialista", quando criado em 1946, até a sua expressão mais atual, marcada pelo viés "educativo" em suas programações. Não se pretende neste capítulo discutir o melhor lazer aos comerciários, sendo o objetivo deste estudo questionar em quais proporções a instituição contribuiu ao entendimento do lazer como um tempo de realização pessoal mesmo em diferentes momentos da política governamental.

Palavras-chave: Lazer, Serviço Social, Comerciários, Políticas governamentais, Cidade.
Prof. Me. Alexandre Francisco Silva Teixeira

É mestre em História Social, especialista em História, Cultura e Sociedade pela Pontifícia Universidade Católica de São Paulo (PUC-SP). Atualmente, é doutorando no Programa de História da PUC-SP. Compõe a Comissão Científica do Congresso Mundial de Lazer - Brasil/2018. É integrante do Núcleo de Estudos de História Social da Cidade (NEHSC) da PUC-SP.

Email: afst2009@ hotmail.com

Prof. ${ }^{a}$ Dr. ${ }^{a}$ Yvone Dias Avelino

Doutorado em História Econômica pela Universidade de São Paulo (1973) e Pós-Doutorado em História pela PUC-SP (1989). É titular no Departamento de História da PUC-SP, onde atua como docente desde 1971. Integra as comissões consultivas e editorias das seguintes revistas: Oralidades - $R e-$ vista de História Oral (USP); Práxis - Revista Eletrônica de História e Educação (Universidade Jorge Amado, Salvador, BA); Projeto História (PUC-SP); Aurora - Revista Eletrônica de Arte, Mídia e Política (PUC-SP). Coordena - NEHSC da PUC-SP, existente há mais de vinte anos. É editora da revista Cordis Revista Eletrônica de História Social da Cidade - disponível em: <http://revistas. pucsp.br/cordis>.

Email:yvonediasavelino@ uol.com.br 


\section{Abstract}

The central objective of this chapter is to relate governmental political circumstances in Brazil between the years of 1945 and 1982, which influenced the leisure organization to traders in São Paulo City, considering perspectives ranging from the creation of Commerce Social Service in the State of São Paulo, as well as the entire process of its main contributions to leisure studies in Brazil. Some strategies that have made the Institution one of the main influencers in the construction of leisure imaginary in São Paulo City are mentioned in this study; which focused on social actions to traders and service providers, since from an initially "welfarist" profile, when it was created in 1946, to its most current expression, marked by the "educational" bias in its schedules. This chapter does not intend to discuss the best leisure to traders, once this study purpose is to question in what proportions the institution contributed to the understanding of leisure as a time of personal fulfillment even at different moments of government policy.

Keywords: Leisure, Social Work, Commerce, Government policies, City.

\section{Introdução}

A cidade é um palco de possibilidades que evolui à medida que os fenômenos são gerados e vivenciados pelas pessoas que nessa habitam. Está repleta de estímulos sociais e culturais que realizam, restringem e desencantam (SAKAMOTO apud AVELINO; FLÓRIO, 2009, p. 51).

São recentes os estudos sobre a cidade no Brasil, que tomaram significativamente novos rumos para a investigação historiográfica nos últimos anos. Esse novo olhar acerca da urbe surgiu pelo interesse nas transformações que passaram a ocorrer aceleradamente. "No Brasil, nos últimos anos, os estudos sobre a cidade vêm passando por mudanças significativas" (MATOS, 2002, p. 33).

O conjunto de possibilidades no cotidiano da cidade é reflexo das ações criativas realizadas pelas pessoas ou grupos que nessa habitam, as manifestações do lazer e trabalho no ambiente urbano dependem dessas ações. "As opções de trabalho, de lazer e o desenvolvimento sociocultural nela alocados, são definidos a partir dos limites e possibilidades de ação criativa de pessoas e grupos que compõem uma cidade" (SAKAMOTO apud AVELINO; FLÓRIO, 2002, p. 52).

A maioria dos trabalhadores ocupa os bairros afastados, o que pressiona o processo de urbanização em demandas ao bem-estar social. Com planejamentos ainda insuficientes e sempre em descompasso com a expansão urbana, o tempo/espaço ao lazer sempre esteve limitado e reduzido de opções.

A ascensão de Getúlio Vargas ao Governo Federal do Brasil, gestão que durou de 1930 a 1945, agregou às políticas públicas um novo modus operandi para as "questões sociais", as quais até então eram "casos de polícia". As modernizações das estruturas públicas prometiam reorganizar a vida dos cidadãos, principalmente nas grandes cidades. A conclusão, em 1934, da legislação trabalhista foi, para os governistas, o passo transformador nesse sentido, pois na qual o trabalhador passou a ser visto como parte significativa à Nação, que naquele momento estava tomada pelas ideias do Estado Novo. Concomitantes a tal conjuntura política, surgiram os sindicatos patronais organizados em federações e confederações por área de produção, na tentativa de conciliar as classes trabalhistas e seu patronato. "A chamada 'Questão Social' torna-se questão legal, sobretudo em virtude do aparecimento da legislação trabalhista, uma das principais preocupações de Getúlio em seu primeiro governo" (FIGUEIREDO, 1991, p. 21).

Assim, a política nacional na Era Vargas lançou para a Nação brasileira um vasto projeto de reorganização e modernização do Estado, com novas perspectivas para as instituições públicas. Entre tais alterações, propunham para a educação e cultura especial atenção a aspectos ainda não tão destacados pelo setor público, tais como o trabalhador, a infância e juventude.

A partir de 1937, com o Golpe de Estado que implantou efetivamente o "Estado Novo", essas propostas se intensificaram no discurso 
do governo federal, visando à formação do futuro trabalhador brasileiro. Foi então criado - Departamento Nacional da Criança, subordinado ao Ministério da Educação e Saúde. Durante a organização desse departamento surgiram também outros organismos sociais locais, igualmente criados pelo governo, a saber: Legião Brasileira de Assistência, Campanha Nacional dos Educandários Gratuitos, Instituição de Puericultura (DINES, 2012, p. 55).

É importante salientar que a modernização autoritária que orientou as propostas políticas no governo de Getúlio Vargas não se apoiou apenas no assistencialismo, somando-se também a tais propostas um forte pensamento racionalista e de gestão científica da Nação brasileira. Esse formato foi reconhecido também por industriais, comerciantes, engenheiros, sanitaristas e educadores que se mobilizavam de forma autônoma. "Assim, toda uma redefinição de métodos de moralização do proletariado pode ser percebida em diversos campos da atividade social, segundo uma racionalidade que glorifica as ideias da Ciência da técnica e do progresso" (RAGO, 2014, p. 66).

Unificados com tal modernização, alguns grupos da elite econômica se organizaram em meados da década de 1940 e propuseram solucionar algumas "questões sociais", intencionados, principalmente, em dar continuidade em seus negócios e investimentos industriais. Dessa forma, esses grupos representaram a nascente de todo o sistema " $S$ "1 do qual o Serviço Social do Comércio (Sesc) faz parte.

"Assim, identificados com as novas tendências de organização racional e administração científica, eles se sentem autorizados a atribuir a si e não ao Estado a autoridade profissional e a competência

1 "O termo $S$ é uma denominação que se generalizou para descrever um conjunto de instituições inicialmente compostas pelo Sesc, Sesi, Senac e Senai. Após a década de 1990 passou a contar também com o Sebrae (Serviço Brasileiro de Apoio a Micro e Pequenas Empresas), o Sest (Serviço Social do Transporte), o Senat (Serviço Nacional da Aprendizagem do Transporte) e o Senar (Serviço Nacional de Aprendizagem Rural)" (REGO, 2002, p. 12). técnica necessária para modernizar a sociedade brasileira" (WEINSTEIN, 2000, p. 20). Serão eles que, organizando-se após a fim do Estado Novo, conduzirão em meados dos anos 1940 uma atuação mais intensa na sociedade que resultará na criação de instituições como o Sesi, o Sesc e o Senac, buscando atender à área de serviço social da indústria e do comércio sem a intervenção direta do Estado (DINES, 2012, p. 57).

Focados na redução dos impactos negativos que desaceleravam o desenvolvimento industrial, tais como as greves operárias, a baixa nas importações, correntes imigratórias europeias e o esgotamento das condições básicas de organização urbana, os empresários começaram a se alinhar em iniciativas próprias (FIGUEIREDO, 1991, p. 26).

As principais questões sociais passavam pela insuficiência de infraestrutura básica diante da intensa velocidade com que as metrópoles cresciam. O rápido aumento da população urbana colapsou as já precárias estruturas sociais das grandes cidades. A insatisfação do operariado intensificava os movimentos grevistas, os quais interferiram principalmente na produção industrial. A forma como a exploração da força de trabalho era empregada acentuava a pobreza e o rebaixamento das condições de vida. Assim, muitos vagavam pela cidade sem higiene e moradia, enfim, em plena desarmonia social. "As novas populações padeciam com a precária infraestrutura das cidades e com sua própria inexperiência urbana" (ALMEIDA, 1997, p. 57).

Diante de tal pauperização entre as classes trabalhadoras e das greves que ameaçavam o avanço industrial, fez-se imprescindivel que as estruturas públicas e empresariais se mobilizassem para alterar o perfil das cidades. Nesse sentido, tomaram a frente das ações em torno do tempo livre vários setores, entre os quais, a polícia, Justiça, o setor privado e a igreja, logo, não se restringindo ao lúdico e descanso, passando a tratá-los também como uma forma de resposta aos interesses dos diversos setores 
sociais como um negócio. A princípio, a organização dos lazeres negou qualquer integração com o ócio - tal distinção teve como base a ordem dos padrões de decência que instituíam o ócio como coisa imoral. "O ócio induzia à vagabundagem, à capoeiragem e aos vícios prejudiciais ao desenvolvimento físico e moral" (SANT'ANNA, 1994, p. 21).

Por esses fatos, as questões sociais e o lazer no Brasil foram discutidos em âmbitos práticos legais no Ministério do Trabalho e da Justiça, encabeçados pelo ministro Alexandre Marcondes Filho, cujo discurso de posse no Ministério do Trabalho, em dezembro de 1941, já sinalizava para a questão da sindicalização corporativa - nota-se um conjunto de medidas dirigidas especificamente à questão da sindicalização corporativista e aliadas à ideologia ministerial defendida por Marcondes Filho e delineada em sua administração.

Marcondes era um bem-sucedido advogado paulista especializado em Direito Comercial - falências como destaque. Seu tradicional escritório era frequentado pela nata do empresariado de São Paulo, ao que acrescentara sua amizade com o jornalista Assis Chateaubriand, proprietário da cadeia de Diários Associados. Não se tratava, portanto, de um homem que tivesse a política do trabalho como um métier (GOMES, 2008, p. 184).

Essa política ministerial transitou significativamente bem entre os representantes das classes produtoras e pretendia desenvolver ações que englobassem a vida social dos trabalhadores nas seguintes questões: higiene, saúde, estrutura familiar, habitação e lazer.

Entre as iniciativas que ocorreram estava a Conferência Nacional das Classes Produtoras, realizada em Teresópolis, $\mathrm{RJ}$, de 1 a 6 de maio de 1945, então significativa por reunir mais de oitocentas associações de todo o País. Foram debatidos os seguintes temas: o Estado e a ordem econômica; elevação do nível de vida populacional; política da produção agrícola; política de investimentos; energia e transportes; política comercial; política monetária; polí- tica social e trabalhista; política imigratória. A presidência da Conferência esteve a cargo de João Daudt D'Oliveira, que foi o primeiro presidente do Conselho Nacional do Sesc, enquanto que na mesa diretora estavam Euvaldo Lodi, Iris Meimberg, Basílio Machado Neto e Roberto Simonsen. Essa conferência foi um marco que assinalou a tomada de posição e poder dos empregadores brasileiros ao sugerirem a criação do Serviço Social do Comércio (ALMEIDA, 1997, p. 57).

Em 1919, o médico e industrial Jorge Street já havia apontado para questões "progressistas" sobre um novo modelo de patronato e repreendia publicamente o desrespeito às necessidades vitais dos trabalhadores. Seguindo pelo mesmo caminho de um patrão moderno e civilizado, Roberto Simonsen, mesmo antes da Conferência das Classes Produtoras, descrevia a organização do trabalho moderno como processo científico. "Dois anos antes da greve geral de 1917, Simonsen defendia a importância da introdução de um método de racionalização da produção que traria 'a cooperação cordial entre patrões e empregados"' (RAGO, 2014, p. 61).

A Carta da paz social foi o resultado documental do evento realizado pelos empresários em maio de 1945, na Cidade de Teresópolis, RJ, resumindo os debates realizados, como também os caminhos a serem seguidos segundo os interesses dos grupos empresariais. Entre as metas estava a criação de um fundo social destinado a obras e ações que melhorassem a vida do trabalhador no âmbito de seu bem-estar social, por meio de uma obra educativa que fortalecesse a solidariedade, confiança, cultura e o aperfeiçoamento técnico. "Por bem-estar dos trabalhadores entendia-se não só melhoria dos níveis de vida, como também aperfeiçoamento cultural e profissional" (FIGUEIREDO, 1991, p. 28).

A Carta de Teresópolis, como também foi denominada, ao se referir à criação de um fundo social, objetivava uma proposta de conciliação de interesses entre empregadores e empregados. As relações entre esses grupos naquele momento mantinham um tom hostil, o que atrapalhava o avanço da produtividade. 
O "espírito de hostilidade" às demais classes, é algo que foi combatido, pelo menos, na esfera do discurso, a todo custo pelos empresários. Pois o desenvolvimento econômico - leia-se aumento de produtividade - só encontraria condições de se processar num clima de "harmonia social" (FIGUEIREDO, 1991, p. 29).

A mobilização política realizada pelos empresários alcançou o Poder Executivo com sucesso; o presidente da República daqueles anos era o general Eurico Gaspar Dutra, quem ratificou a criação do Sesc, considerando função das forças governamentais a melhoria das condições de vida da população brasileira, principalmente das classes desfavorecidas. Assim, pelo Decreto-Lei n. ${ }^{\circ} 9.853$, de 13 de setembro de 1946, determinou: i) a criação do Sesc pela Confederação Nacional do Comércio (CNC), com a finalidade de fortalecer os valores ao bem-estar social, moral e cívico da população; ii) que as formas de administração se estabeleçam descentralizadas e presididas por representantes sindicais do comércio e de serviços nas esferas nacional e regionais; iii) que os recursos de capital sejam calculados a partir de um percentual da folha de pagamento e recolhidos compulsoriamente dos empregadores de estabelecimentos representados por sindicatos subordinados ao CNC em concordância com a Consolidação das Leis do Trabalho (CLT).

O presidente da República na época, general Eurico Gaspar Dutra, baseando-se no Artigo 180 da Constituição, ratificou a criação do Sesc considerando que era função do Estado "melhorar as condições da vida da coletividade" e das classes desfavorecidas, acreditando assim, que o Sesc atuaria no sentido do "fortalecimento da solidariedade entre as classes, do bem-estar da coletividade comerciária e, bem assim, para a defesa dos valores espirituais em que se fundam as tradições da nossa civilização" (DINES, 2012, p. 64).
Assim, a estrutura jurídica do Sesc foi composta pelo Decreto-Lei n. ${ }^{\circ} 9.853$, de 13 de setembro de 1946, que instituiu a organização; tal como pelo Decreto n. ${ }^{\circ}$ 61.836, de 5 de dezembro de 1967, que aprovou o Regulamento do Sesc e que se manteve na Lei Magna de 1988.

A partir desse arcabouço jurídico, os "servicos sociais" mantidos pelo Poder Privado representaram singular espaço nas estruturas legais do Brasil. Essas entidades foram definidas como paraestatais e, por isso, com autonomia jurídica, administração descentralizada, a fim de elegerem os seus diretores sem ingerência estatal por meio de acordos sindicais, com liberdade na gestão de seu patrimônio e prestação de contas a posteriori ao Tribunal de Contas.

Figura 1 - Conferência de Teresópolis, $\mathrm{RJ}$, em 1945.

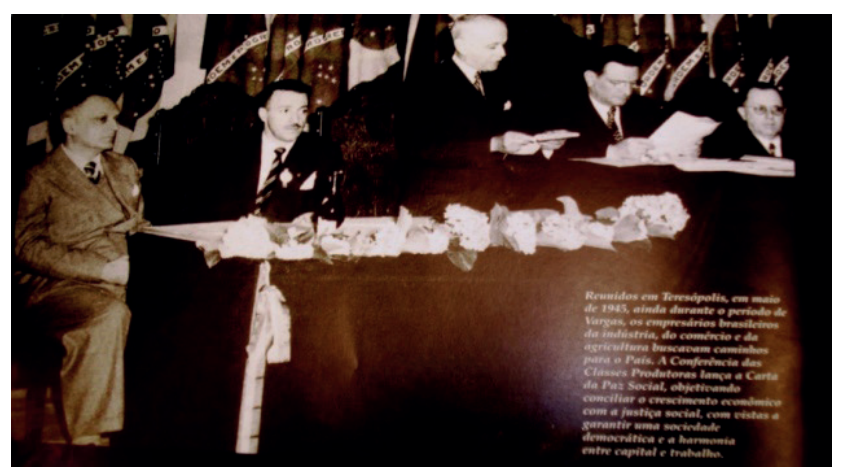

Fonte: Almeida (1997, p. 24).

A Figura 1 se refere ao momento de leitura da Carta da paz social, produto da Conferência na qual os representantes se comprometeram publicamente, a partir de seus próprios recursos, à promoção de ações que melhorassem as condições sociais dos trabalhadores do comércio. Essa fotografia foi divulgada entre os comerciários como um marco simbólico do princípio da instituição, de modo que a seguinte mensagem, editada em 1997, acompanhava essa foto em uma publicação comemorativa.

Reunidos em Teresópolis, em maio de 1945 , ainda durante o período de Vargas, os empresários brasileiros da indústria, do 
comércio e da agricultura buscavam caminhos para o País. A Conferência das Classes Produtoras lança a Carta da paz social, objetivando conciliar o crescimento econômico com a justiça social com vistas a garantir uma sociedade democrática e a harmonia entre capital e trabalho.

A presença de bandeiras da Nação brasileira enfileiradas ao fundo é um marco dos primeiros anos da Instituição, dado que o uso de elementos simbólicos nacionais agregava legitimidades nacionalistas à filosofia de ação do Sesc.

A figuração da bandeira nacional nos eventos promovidos pelo Sesc cauciona, simbolicamente, suas ações. Pode-se dizer que a bandeira nacional funcionava como um signo a lembrar do lugar de poder da Instituição. A referência patriótica legitima, portanto, sua filosofia de ação (LIMA, 2014, p. 178)

Por volta de 1958, em seu lugar começou a surgir o símbolo do Sesc na forma de bandeira ou estandarte, comumente figurando em eventos públicos e solenidades oficiais.

Figura 2 - Inauguração do restaurante do Sesc/Alcântara Machado (1959).

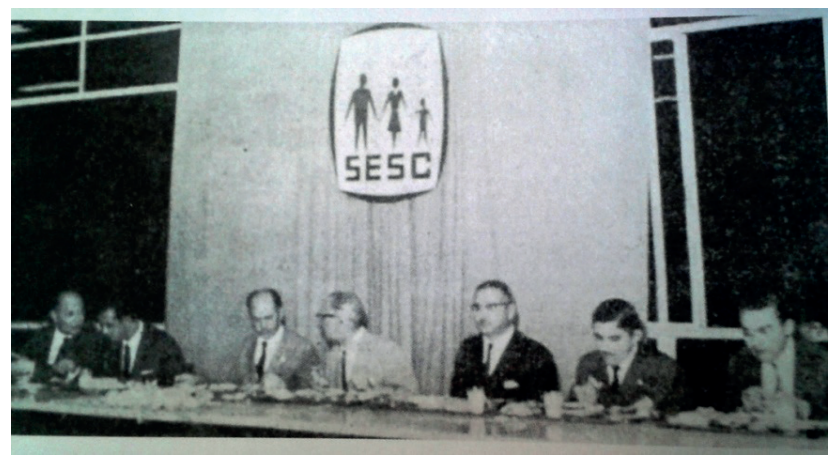

Fonte: Revista do Comerciário, p. 181, nov./dez. 1959.
Figura 3 - Desfile de 7 de Setembro realizado pelo Centro Social da Cidade de São Carlos, SP (1959).

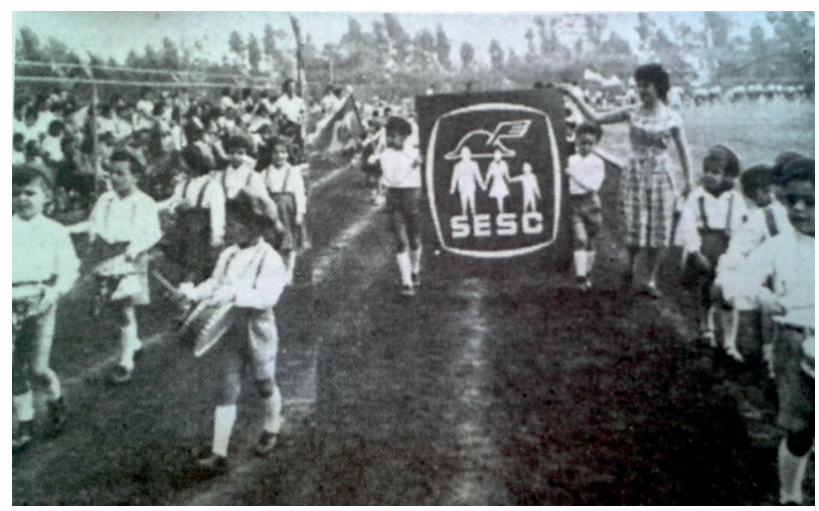

Fonte: Revista do Comerciário, p. 183, nov./dez. 1959.

As figuras 2 e 3 documentam a utilização do símbolo da instituição que, aos poucos, passou a substituir a bandeira nacional como lugar central em seus eventos. A Figura 2 é um registro da inauguração do restaurante do Sesc/ Alcântara Machado, enquanto que a Figura 3 se refere ao desfile de 7 de Setembro realizado pelo Centro Social da Cidade de São Carlos, SP, em 1959.

A substituição da bandeira nacional pelo estandarte com o escudo da instituição não diminuiu a importância que o Sesc deu aos rituais cívicos e ao nacionalismo, ainda corrente, além de fortalecer a construção de uma marca ideológica que, nas décadas seguintes, direcionou grande parte do imaginário do lazer na Cidade de São Paulo.

Dessa forma, as atividades de lazer eram estruturadas e direcionadas intencionalmente para atenuar os problemas entre patrões e empregados. Na maioria das vezes as reivindicações dos trabalhadores eram por menos horas de trabalho, já a iniciativa de ocupação do tempo oposto ao trabalho com atividades lúdicas e de integração partiu do patronato.

Tais propostas com vistas para o avanço das forças produtivas em conjunto com melhorias nos padrões de vida do trabalhador urbano processaram as questões sociais com 
movimentos semelhantes ao período estadonovista, porém, independentes. "Essa forma de atuação mostra uma visão dos empresários semelhante à do Estado Novo, só que desta vez sua ação é conduzida de modo autônomo" (DINES, 2012, p. 64).

Assim, considerava o trabalho um direito e dever nacional ao mesmo tempo em que deixava explícito aos representantes sindicais quem seriam os dirigentes para a administração dos fundos às questões sociais a que se propunham.

A primeira unidade do Sesc no Brasil foi instalada em 1946, na Cidade do Rio de Janeiro, no bairro Engenheiro de Dentro - as suas principais atividades eram maternidade, infância e combate à tuberculose.

No Estado de São Paulo, o Conselho Regional do Sesc teve o seu primeiro aporte físico em uma sala concedida pela Associação Comercial de São Paulo, localizada no Viaduto da Boa Vista, 57. Nesse momento, o Conselho Regional se formou por representantes de diversos setores da sociedade, tais como dirigentes sindicais e conhecedores dos problemas sociais. Os planos iniciais se voltavam a prestar assistência aos comerciários e prestadores de serviço em diversas áreas, principalmente no auxílio dos setores de saúde, da alimentação e higiene. Esse conselho também previa ações em defesa do salário real do comerciário, da melhoria das condições de habitação e transporte, do conhecimento dos preços de custo de artigos de consumo generalizado.

Sua primeira equipe de funcionários teve como previsão orçamentária cem milhões de cruzeiros para seiscentos mil comerciários inscritos; o horário de funcionamento era das $6 \mathrm{~h}$ às $22 \mathrm{~h}$, com uma equipe de quatro servidores: um diretor, um encarregado de secretaria, uma datilógrafa e um office boy. Ainda em 1949, a Instituição alcançou quatrocentos funcionários e uma média de sessenta mil atendimentos; em novembro desse mesmo ano lançou o jornal $\mathrm{Em}$ Marcha, com tiragem de dez mil exemplares.
Figura 4 - Primeira edição do jornal Em Marcha.

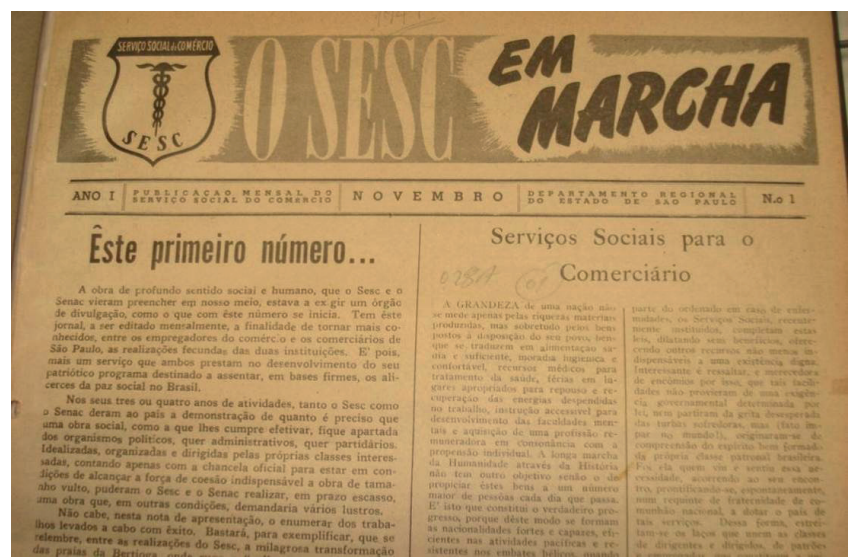

Fonte: acervo Sesc Memórias, Sesc São Paulo.

Esse jornal era direcionado ao comerciário com o intuito de informá-lo sobre as atividades realizadas pela Instituição. O Departamento Regional do Estado de São Paulo empregou o sistema de informação de suas atividades nos moldes jornalísticos sobre o fato ocorrido ou acerca do assunto dos empreendimentos realizados (LIMA, 2014, p. 30). Foi o principal veículo de divulgação do Sesc, no qual se encontram noticiadas atividades desenvolvidas nos Centros Sociais, ${ }^{2}$ inaugurações de novos espaços, resultados de campeonatos esportivos, cursos - de culinária, pré-natal e primeiros socorros -, passeios de grupos no Sesc/Bertioga e o "espetacular" concurso de robustez infantil.

\begin{abstract}
Espetacular porque esse tipo de criança foi valorizado numerosas vezes em concursos de robustez e de beleza infantil, cujo apogeu ocorreu entre os anos de 1930 e 1940. Centenas de bebês e crianças foram considerados verdadeiros representantes do futuro nacional. $\bigcirc$ mérito estava em seus diminutos corpos que deviam espelhar vigor e saúde (SANT'ANNA, 2016, p. 59).
\end{abstract}

Ao final da década de 1940, vários centros sociais foram inaugurados pela Capital paulista: Santana, Tatuapé, Bela Vista, Água Branca

2 "Os 'Centros Sociais' foram um formato inicial marcado por um período de ações assistencialistas, funcionavam em espaços, geralmente, adaptados" (ALMEIDA, 1997, p. 60). 
e o restaurante do comerciário "Alcântara Machado". Essas unidades do Sesc/SP, com exceção do restaurante do comerciário, foram instaladas em residências de aspecto familiar e representavam unidades-eixos e irradiadoras de ações que deveriam alcançar os trabalhadores do comércio, assim como os seus lares - por meio de práticas persuasivas nos setores sociais da saúde, recreação, cultura e sociabilidade dos esportes (DINES, 2012, p. 65-66).

Em seu $15^{\circ}$ aniversário, o Departamento Regional do Estado de São Paulo contava com dezoito unidades - na Capital e interior - e com mil servidores. Em 1961 ocorreu a III Convenção de Técnicos em Macaé, RJ, Conferência que avaliou as heterogeneidades social e econômica da população comerciária, atualizando o plano de ação do Serviço Social do Comércio em todo o País, sendo estimulada por uma nova demanda que emergia da expansão de veículos midiáticos, casos da televisão e do cinema, assim como das políticas de ação cultural e de uma rápida transformação nos rumos da economia nacional.

O período de expansão do trabalho do Sesc também corresponde a um momento de franco desenvolvimento para o País, principalmente entre os anos de 1955 e 1960, no governo Juscelino Kubitscheck, cujo Programa de Metas foi um projeto de dotação de infraestrutura básica para o País, ou seja, de grande industrialização, modificando os rumos da economia brasileira no contexto internacional (GALANTE, 2018, p. 17).

Tais estudos geraram reestruturações que englobaram estratégias de crescimento, expansão das ações na programação e descentralização do plano administrativo; ademais, abriram novas experiências no plano técnico- -teórico. Assim, nos resultados das pesquisas sociais e econômicas surgiram os novos conceitos do lazer, os quais pautados na educação e cultura (DINES, 2012, p. 75).

A criação da colônia de férias em Bertioga onde atualmente está implantado o Sesc/ Bertioga foi um dos primeiros registros a considerar o lazer em uma concepção mais ampla dentro da instituição, mas a grande influência teórica às práticas do lazer foi o contato com o sociólogo Joffre Dumazedier, na década de 1960.

Joffre Dumazedier, foi um dos primeiros
estudiosos a teorizar possibilidades de
desenvolvimento por meio de atividades
de lazer, tema que se destaca nas Ciên-
cias Sociais na década de 1960 e que está
relacionado às discussões em pauta, na
época, sobre as novas formas de trabalho
e as novas divisões entre tempo de tra-
balho e tempo livre (OLIVEIRA, 2009, p. 65).

Assim, os pressupostos ao lazer na Instituição se relacionavam ao avanço das capacidades físicas e intelectuais. Nesse sentido, o seguinte fluxograma se refere às possibilidades ao lazer segundo Dumazedier, quem afirma que - lazer pode gerar resultados que the conferem características libertárias; logo, o tempo ao lazer na concepção desse pesquisador é o momento de diversão, descanso e desenvolvimento (SILVA, 2013, p. 38).

Figura 5

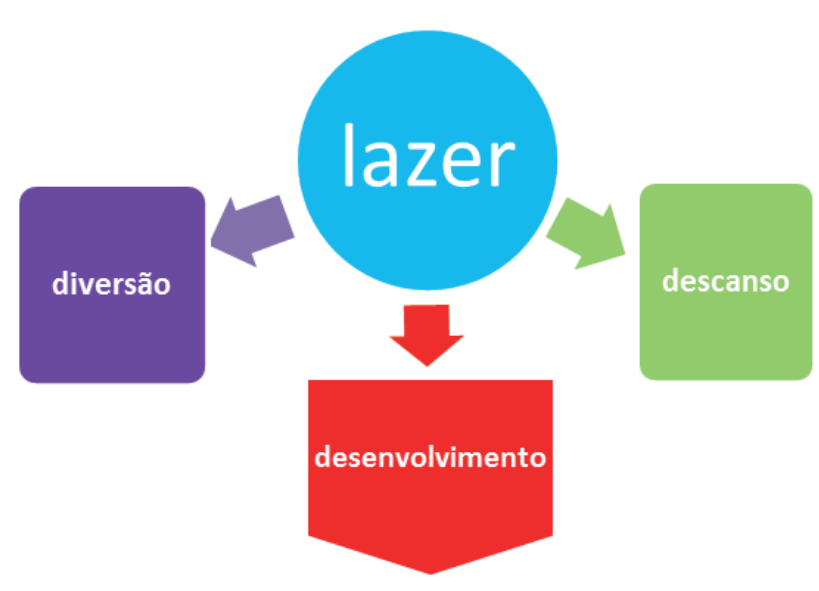

Fonte: elaborada pelos autores 
Em proporções não tão intensas como as de Dumazedier, o pensamento do filósofo e historiador italiano Etori Gelpi, membro da Organização das Nações Unidas para a Educação, a Ciência e a Cultura (Unesco), exerceu também influência quando esteve presente no Brasil a convite da Instituição para ministrar um curso sobre lazer e educação. Assim, esses dois pesquisadores foram acolhidos pelo Sesc/SP para redefinir as suas ações sociais voltadas às novas demandas do lazer (OLIVEIRA, 2009, p. 65).

O foco educativo das ações do Sesc surgiu durante o trânsito da superação do formato assistencialista focado na instrumentalização técnica. A valorização dos novos conceitos sobre o lazer na Instituição partia de pressupostos educativos e civilizatórios dirigidos aos comerciários. Assim, mesmo com a ascensão das forças militares, que inviabilizavam intenções educativas que não fossem de seu interesse, as instâncias privadas envolvidas com o Serviço Social do Comércio insistiam na promoção social.

Portanto, o lazer transitou por diferentes lugares no cotidiano das populações urbanas, comumente orientado pela importância dada pelas elites ao tempo livre do trabalhador.

Entre as estratégias da Instituição nesse período, torna-se importante destacar as Unidades Móveis de Orientação Social (Unimos) e a inauguração do Centro Cultural e Desportivo Carlos de Souza Nazareth.

O funcionamento das Unimos compreende as décadas de 1960 a 1970, então criadas com a finalidade de levar lazer e cultura aos locais da Cidade de São Paulo e do interior paulista onde ainda não havia um centro cultural do Sesc. Tais equipamentos funcionavam em um furgão ocupado por três orientadores sociais que dispunham de materiais para a realização de atividades comunitárias de cunho social, cultural e esportivo. Sua ação era definida em conjunto com voluntários e líderes locais, lideranças que traziam para os espaços públicos as contribuições que, até então, ficavam à disposição de um público restrito em salas de clubes, mas longe dos olhos da população e representava uma oportunidade para descobrir, expor e divulgar talentos locais.

\begin{abstract}
As Unimos - Unidades Móveis de Orientacão Social - surgiram no início dos anos 1960, com o objetivo de promover atividades de lazer e cultura nas cidades do interior do Estado que não contavam com centros sociais do Sesc. As Unimos trabalhavam sempre em conjunto com voluntários e os líderes comunitários locais e podiam ficar meses em uma cidade. Uma característica marcante do projeto é que não havia uma programação prévia fechada, havia ideias, mas a sua concentração acontecia em conjunto com a comunidade local (LIMA, 2014, p. 257).
\end{abstract}

Figura 6 - Unimos.

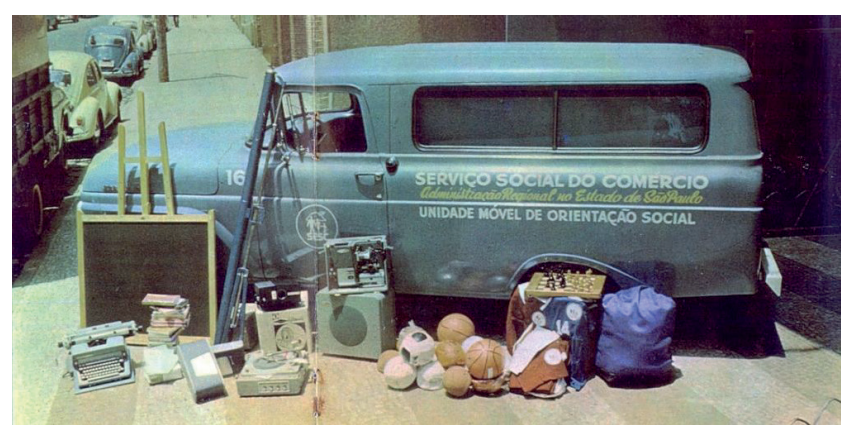

Fonte: Galante (2018, p. 17).

Tratava-se de uma nova concepção de equipamento de lazer, diferenciando-se dos centros sociais adaptados em antigos casarões alugados em pontos espalhados pela Capital e interior paulista.

O Sesc/Vila Nova, ou Centro Cultural e Desportivo Carlos de Souza Nazareth, atual Sesc/ Consolação, inaugurado em 1967, foi a primeira unidade do Sesc construída com uma arquitetura que previa unir diferentes espaços destinados ao tempo livre dos comerciários em uma só edificação, implantando um outro conceito territorial ao lazer na Instituição. Assim, distribuído pelos andares foram construídas piscina, 
ginásio de esportes, teatro, clínica odontológica, restaurante e salas para atividades.

Tratou-se de um marco para a Cidade de São Paulo, que à época respondia a uma nova demanda ao lazer urbano da classe trabalhadora com um olhar inédito e estratégico em seu caráter institucional. "O Sesc Vila Nova inaugurou outro momento da trajetória do Sesc, marcada pelo investimento nos equipamentos urbanos que garantem a realização de vasto programa de atividades culturais e esportivas" (OLIVEIRA, 2009, p. 170).

No caso, havia um território preparado para isso, onde os seus visitantes passaram a reagir pela possibilidade da escolha no espaço que os acolheria. "A compreensão do lazer pode assumir diferentes papéis e funções na vida de um sujeito, que variam a partir das circunstâncias em que ele vivencia seu tempo livre e que influenciam as ações dos centros culturais" (SILVA, 2013, p. 38).

A Instituição já fomentava novas estratégias de ação internamente, antes mesmo da inauguração da mencionada unidade no centro da Cidade de São Paulo, que se alinhavam às teorias sociológicas sobre o lazer de Joffre Dumazedier, abordagem já presente no cenário do Sesc. O coordenador das Unimos, Renato Antônio Quadros de Souza Requixa, quem produziu significativa bibliografia sobre lazer e esteve à frente da Diretoria Regional do Sesc em São Paulo de 1976 a 1984, havia se interessado pelo pensamento do sociólogo francês.

Durante o tempo que se dedicou a coordenar o trabalho das Unimos, Renato Requixa recebeu, de um de seus assistentes que havia viajado à Suécia para fazer uma pesquisa sobre Sociologia do Trabalho, uma revista com um artigo assinado por Joffre Dumazedier (GALANTE, 2018, p. 21).

O momento político das estratégias mencionadas nas práticas do lazer, após o golpe civil-militar de 1964, ${ }^{3}$ foi atravessado pelos

3 O período ditatorial iniciado em 1964 durou vinte e um anos, servindo de palco para o revezamento de cinco princípios políticos desse período - desenvolvimento e progresso -, de modo que a Instituição precisou deixar nítida a mensagem de ajuste e adequação aos comportamentos sociais impostos. As forças ideológicas que estavam no poder do Estado admitiam o lazer como prática social esportiva, educacional, integradora e salutar, desde que contribuíssem à estética cívica relacionada à ocupação do tempo livre com atividades produtivas segundo os moldes dos planos do governo vigente.

\begin{abstract}
A primeira impressão que temos ao lancar nossas atenções sobre essa época é a de que vivíamos simultaneamente dois movimentos distintos e opostos: por um lado, a exaltação a uma série de conteúdos do tempo livre permeados de ludicidade e, por outro, a ênfase no trabalho preconizada pelo Governo Militar e fortalecida pela política do "Milagre Econômico", que contribuiu para reduzir drasticamente o tempo livre da maior parte dos assalariados. Assim, poder-se-ia imaginar que a exaltação a determinados usos do tempo livre, a recomendação e a legitimação de certas atividades e espaços de diversão consistiam num lado a salvo do rosto pálido da ditadura militar (SANT'ANNA, 1994, p. 9).
\end{abstract}

Foi preciso limpar dos conceitos sobre o lazer qualquer resíduo que o relacionasse ao ócio, vício ou pecado. Ao lazer foi agregada a identidade produtiva, que fundava valores de obediência e rendimento aos habitantes citadinos. Nesse momento houve um apelo social sensacionalista que pretendia salvar a juventude da influência negativa dos hippies, pois estes estimulavam o exagero sexual, consumo de drogas e a vagabundagem. Assim, as práticas

generais na Presidência da República. Além disso, a política econômica continuou optando pelo aproveitamento do capital estrangeiro (GHIRALDELLI JUNIOR, 2006), gerando um modelo que concentrava a renda a uma pequena parcela da população e submetia a maior parte dos trabalhadores ao arrocho salarial. A abertura ao capital internacional, a instalação de multinacionais e o grande desenvolvimento industrial marcaram esse período, conhecido como Milagre Econômico (GALANTE, 2018, p. 19). 
esportivas eram consideradas catalisadores que bem orientavam a juventude marginalizada e vulnerável a tais perigos e influências.

Mesmo empenhados em corrigir e colocar fim a determinadas práticas sociais, o que chama a atenção é a semelhança entre os programas de lazer e os discursos político e econômico do regime militar. "É esta semelhança que perturba: como foi possivel delegar à esfera do lúdico e tempo livre responsabilidades tão amplas como as de promover a integração social e o ajustamento da ideologia vigente?" (SANT'ANNA, 1994, p. 58).

Em 1969, o Seminário Sobre Lazer: Perspectivas para uma Cidade que Trabalha, promovido pela Secretaria do Bem-Estar em conjunto com - Sesc, abriu espaço para a discussão do tema com diversos setores, tais como urbanistas, professores, universidades e empresários.

Em 1969, o Sesc de São Paulo e a Secretaria de Bem-Estar do Município resolveram empreender um evento público para discussão do tema, um seminário de estudos aproximando universidade, planejadores e trabalhadores sociais. [...] A repercussão do Seminário [...] foi perto de catastrófica. [...] De um lado, a favor do tema, devem ser lembrados o Sesc e alguns setores públicos minoritários, sobretudo de urbanistas, que não se conformavam com a degradação dos espaços urbanos e com a morte do Centro Histórico. Havia, também, os professores de Educação Física e os recreadores escolares, que se sentiam marginalizados em face da tônica dominante na escola. De outro, contrários, havia os empresários, os "donos" do trabalho, em parceria inusitada com a Sociologia estabelecida, sobretudo da USP e da PUC, sem deixar de mencionar a parcela majoritária de assistentes sociais e profissionais que se dedicavam ao cuidado das populações carentes (CAMARGO apud GALANTE, 2018, p. 22).
O Sesc teve papel fundamental para o aprofundamento dos estudos sobre o lazer no Brasil não somente pelos grandes eventos e ações que projetou na sociedade, mas por iniciativas de sistematização e produção de conhecimento nessa área. A criação, em 1978, do Centro de Estudos de Lazer (Celazer) por Renato Requi$x a$, diretor regional do Sesc no Estado de São Paulo, foi uma dessas ações que aprofundaram a importância do lazer como meta social.

Celazer surgiu de um contexto político-institucional favorável ao aprofundamento das questões do lazer, motivado tanto pelo desejo pessoal da gestão da Instituição à época, quanto pelo próprio momento em que o País, em meio ao desenvolvimentismo propagado pelo governo militar, intensificava as preocupações sobre o lazer e os usos do tempo livre dos trabalhadores, com vistas a um direcionamento capaz de imprimir na populacão a ideia do uso adequado do tempo do não trabalho em benefício dos valores, da ordem, da recuperação física e da produtividade necessária ao desenvolvimento do País (GALANTE, 2018, p. 82).

A junção de aspectos socioeducativos no tempo de lazer representava um resultado de tais estudos realizados pela Instituição, gerando ressignificação no planejamento de suas programações. Passaram a ter mais destaque a festa, o passeio, a dança, viagem, as artes e o desenvolvimento físico/esportivo no tempo/espaço organizado pelo Sesc. Os centros culturais e desportivos da Instituição se abriram à fruição cultural múltipla, marcada pela descontração do tempo oposto ao trabalho em um estado de "bricolagem".

[...] o que caracteriza a bricolagem é a elaboração de conjuntos estruturados não diretamente com outros conjuntos estruturados, mas utilizando resíduos 
e fragmentos [...]. Nesse sentido são "pré-constrangidos", isto é, mesmo no interior de um novo arranjo, conservam marcas determinadas pelo uso original para o qual foram concebidos ou pelas adaptações que sofreram, em vista de outros empregos (LÉVI-STRAUSS apud MAGNANE, 2003, p. 142).

Desde 1961, a Instituição pretende promover a educação social pelo lazer balizado nas propostas de Joffre Dumazedier e fundamenta essa prática ao unir o lazer, a educação e cultura. Sua proposta ao lazer torna-se abrangente e variada ao acolher diferentes camadas sociais em um mesmo espaço/tempo onde se cruzam o tradicional e a vanguarda, o erudito e popular.

A inauguração do Sesc/Pompeia, em 1982, projetou, mais uma vez, a Instituição para um lugar de destaque no tecido urbano. Com projeto arquitetônico de Lina Bo Bardi, a Unidade "Fábrica da Pompeia" passou a ser considerada como um novo modelo político de ação do Sesc ao colocar o esporte no mesmo patamar das ações culturais. As suas programações marcaram o lugar do "novo" no sentido semelhante ao de "vanguarda". A partir desse momento, as programações, de modo geral, tiveram como fim maior planejar atividades ou vivências multiculturais.

Em linhas gerais, os caminhos da Instituição seguem uma maneira de pensar as pluralidades políticas no decorrer do tempo como fatores indiretos em suas evoluções, porém, apresentam certa coerência ideológica entre os poderes públicos e privados nos modos de organizarem o lazer.

Nesse sentido, a seguinte timeline propõe uma vista cronológica entre alguns acontecimentos na política e as principais linhas conceituais que estruturaram a Instituição em sua organização interna:
Figura 7.

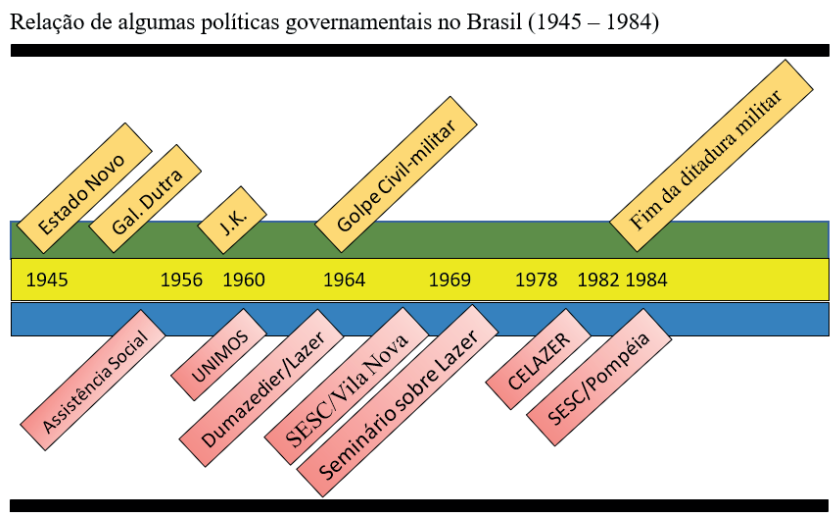

Evolução conceitual nas ações do Sesc/SP (1945 - 1984)

Desde a "questão social" enfatizada pelo Estado Novo até a redemocratização nacional com o fim da ditadura militar, a Instituição não perdeu o foco de suas ações na esfera do lazer. Após 1982, o Sesc amadureceu os seus conceitos e as suas práticas por motivações internas organizadas em grupos de estudo que agregaram novos modos de pensar e fazer o lazer.

Assim, no decorrer dos anos se transformou entre avanços e permanências em suas estratégias de ação, prioritariamente, destinadas aos comerciários, prestadores de serviço e seus familiares.

\section{Referências}

ALMEIDA, M. de. Sesc São Paulo - uma ideia original. São Paulo: Lazuli; Sesc, 1997.

AVELINO, Y. D.; FLÓRIO, M. (Org.). Polifonias da cidade. São Paulo: D’Escrever, 2009.

CAMARGO, L. O. L. O que é lazer. São Paulo: Brasiliense, 1992.

CARTA da paz social. Conferência das Classes Produtoras. Teresópolis, RJ, 1945.

CUNHA, N. Dicionário Sesc: a linguagem da cultura. São Paulo: Perspectiva; Sesc, 2003.

DE MASI, D. O ócio criativo. Rio de Janeiro: Sextante, 2000.

DINES, Y. S. Cidadelas da cultura no lazer: uma reflexão em Antropologia sobre o Sesc São Paulo. São Paulo: Sesc, 2012. 
DUMAZEDIER, J. Sociologia empírica do lazer. São Paulo: Perspectiva; Sesc, 2008.

FIGUEIREDO, B. G. A criação do Sesi e Sesc: do enquadramento da preguiça à produtividade do ócio. 1991. Dissertação (Mestrado em Serviço Social) - Instituto de Filosofia e Ciências Humanas do Departamento de História da Universidade Estadual de Campinas, Campinas, SP, 1991.

GALANTE, R. C. Memórias do Celazer: influências e contribuições para os estudos do lazer no Brasil. 2018. Tese (Doutorado)-Universidade Estadual de Campinas, Campinas, SP, 2018.

GOMES, C. L. Lazer, trabalho e educação - relações históricas, questões contemporâneas. Belo Horizonte, MG: UFMG, 2008.

ISAYAMA, H. F.; LINHARES, M. A. (Org.). Sobre lazer e política: maneiras de ver, maneiras de fazer. Belo Horizonte, MG: UFMG, 2006.

LEMOS, C. L. N. Práticas de lazer em São Paulo atividades gratuitas nos Sesc Pompeia e Belenzinho. 2005. Dissertação (Mestrado em Ciências Sociais) - Pontifícia Universidade Católica de São Paulo, São Paulo, 2005.

LIMA, S. F. de. As imagens da imagem do Sesc: contextos de uso e funções sociais da fotografia na trajetória institucional. São Paulo: Sesc, 2014.
MAGNANE, J. G. C. Festa no pedaço. São Paulo: Unesp, 2003.

MATOS, M. I. S. de. Cotidiano e cultura: história, cidade e trabalho. Bauru, SP: Edusc, 2002.

OLIVEIRA, P. S. Artesanato de brinquedo: trabalho ou lazer? Leituras Celazer. São Paulo: Sesc, 1980.

RAGO, M. Do cabaré ao lar. São Paulo: Paz e Terra, 2014.

SAKAMOTO, C. K. Cidade - um ambiente psicológico de suporte ao desenvolvimento humano. In: AVELINO, Y. D.; FLÓRIO, M. (Org.). Polifonias da cidade. São Paulo: D’Escrever, 2009.

SANT'ANNA, D. B. de. O prazer justificado história e lazer (1969-1979). São Paulo: Marco Zero, 1994.

SILVA, M. F. da. Centros culturais: análise da produção bibliográfica. Gestão estratégica da hospitalidade. 2013. Dissertação (Mestrado em Hospitalidade) - Universidade Anhembi Morumbi, São Paulo, 2013. 
